\title{
New Matrix Tablet from Okra Gum: Effects of Method of Preparation and Gum Concentration on Tablet Properties
}

\author{
Bakre Lateef Gbenga ${ }^{*}$, Abimbola Zulikha \\ Department of Pharmaceutics and Pharmaceutical Technology, Olabisi Onabanjo University, Sagamu, Nigeria. \\ Email: *lateefbakr@yahoo.com
}

Received May $21^{\text {st }}, 2013$; revised June $28^{\text {th }}, 2013$; accepted July $14^{\text {th }}, 2013$

Copyright (C) 2013 Bakre Lateef Gbenga, Abimbola Zulikha. This is an open access article distributed under the Creative Commons Attribution License, which permits unrestricted use, distribution, and reproduction in any medium, provided the original work is properly cited.

\begin{abstract}
The objective of this investigation is to study the effect of methods of preparation and concentration of gum on the compressional and mechanical properties of Okra gum matrix. The compressional behavior of Okra gum matrices prepared by direct compression and wet granulations is analyzed using density measurements, Heckel and Kawakita analysis while the mechanical properties of the formulations were assessed using crushing strength (CS) and friability (FR) as well as CSFR ratio. Formulations prepared by direct compression had lower $\mathrm{P}_{\mathrm{k}}$ values than those prepared by wet granulation while there was no significant difference between $\mathrm{P}_{\mathrm{y}}$ values of formulations prepared by direct compression and wet granulations. Therefore, formulations prepared by direct compression underwent plastic deformation more easily and rapidly than those prepared by wet granulation. The results show that $D_{B}$ values increased with decrease in concentration of the gum and granules undergo higher degree of fragmentation than powders. Formulations containing $90 \%$ w/w Okra gum exhibited the highest amount of total plastic deformation and gave the best packing. Tablets prepared by direct compression showed lower bond strength and higher friability values than those prepared by wet granulations. The crushing strength generally decreases with a decrease in the concentration of the gum while there was an inverse relationship between friability and gum concentration. CSFR decreases with a decrease in gum concentration and tablets prepared by wet granulations showed significantly higher values of CSFR $(p<0.001)$ than those prepared by direct compression. The results suggest that the concentration of gum and the method of preparation of materials for compression are critical factors in the formulation of Okra gum matrices with acceptable compressional and mechanical properties.
\end{abstract}

Keywords: Okra Gum; Wet Granulation; Direct Compression; Compressional and Mechanical Properties

\section{Introduction}

Natural polymers and their semi-synthetic derivatives gained popularity in development of novel drug delivery systems. They are degradable, compatible with bioactive agents, readily available, and possess ability for chemical modifications as well as have functional versatility [1-4]. A large number of natural polymers that are used for drug delivery are non starch polysaccharides, many of which are hydrogels with high swelling ratios and capable of causing large viscosity increases in aqueous solutions even at small concentrations [5]. These are among the properties that make them overtly dependable in several conventional and novel drug delivery systems $[6,7]$. Thus, natural biopolymers like Okra gum along with

${ }^{*}$ Corresponding author. their modification products offer a wide range of properties and applications.

Okra gum obtained from the fruits of Abelmuscus esculentus, is a polysaccharide consisting of D-galactose, L-rhamnose and L-galacturonic acid [8]. Okra gum had been evaluated as binder in tablet dosage formulation $[9,10]$ and as a control release agent in modified release matrices in comparison with sodium carboxymethyl cellulose (NaCMC) and hydroxypropylmethylcellulose (HPMC) using paracetamol as the model drug. Okra gum matrices provided controlled release of paracetamol for more than $6 \mathrm{~h}$ and the release rates followed time-dependent kinetics. Okra gum compared favourably with $\mathrm{NaCMC}$, and a combination of Okra gum and $\mathrm{NaCMC}$, and further addition of HPMC resulted in a near zero order release of paracetamol from the matrix tablet [11]. 
In the manufacture of matrix tablets, measures are taken to ensure that they possess a suitable mechanical strength to avoid crumbling or breaking on handling or subsequent processing and good release profile. The effect of formulation factors on the properties of matrix tablets made from various natural gums has been widely reported [12]. However, there appears to be little information on the effect of method of preparation on the properties of Okra gum matrices. Thus, the aim of the present investigation is to study the effect of concentration of gum and the method of preparation on the compressional and mechanical properties of Okra gun matrices.

\section{Materials and Methods}

\subsection{Material}

The materials used were Metformin (Lifeline Pharmaceutical, Mumbai), acetonitrite, sodium carboxymethyl cellulose and magnesium stearate (BDH chemicals, UK). Okra gum was isolated from okra pods at the Pharmaceutics Laboratory, Olabisi Onabanjo University, Nigeria.

\subsection{Extraction of Gum from Okra Pods}

Okra gum was extracted from the pods of okra fruit. The fruits were cleaned, washed, sliced, crushed and then macerated in distilled water for 10 hours with intermittent stirring. The mucilage was filtered through a white muslin cloth to extract the gum and acetone was added to precipitate the extracted gum. The gum was then filtered under vacuum to remove acetone and dried in a dessicator.

\subsection{Preparation of Granules}

Batches (200 g) of the formulation of Okra gum and metformin with or without sodium carboxymethyl cellulose were dry-mixed for $5 \mathrm{~min}$ in a Kenwood planetary mixer. Particle density was determined by using the Helium pycnometer. The dry mixed batches were moistened with $15 \mathrm{~mL}$ of distilled water and mixed in a Kenwood planery mixer. Massing was continued for $5 \mathrm{~min}$ and, the wet masses were granulated by passing them through a number 12 mesh sieve $(1400 \mu \mathrm{m})$, dried in a hot air oven for $18 \mathrm{~h}$ at $50^{\circ} \mathrm{C}$, and resieved through a 16-mesh sieve $(1000 \mu \mathrm{m})$. The granules were stored in air tight containers.

\subsection{Determination of Precompression Density}

The particle density was determined by the pycnometer method using the liquid immersion technique with benzene as the displacement fluid. The bulk density of formulation at zero pressure (loose density) was determined by pouring the granules at an angle of $45^{\circ}$ through a funnel into a glass measuring cylinder with a diameter of 21 $\mathrm{mm}$ and a volume of $50 \mathrm{~mL}$. Determinations were made in triplicate. The relative density, $\mathrm{D}_{0}$, of each powder was obtained from the ratio of its loose density to the tapped density.

\subsection{Tablet Compression}

Okra gum matrix $(300 \mathrm{mg})$ were prepared by direct compression of each mixture containing $0 \%, 10 \%, 20 \%, 40 \%$ drug (Metformin) in Okra and 10\% drug in Sodium carboxymethyl cellulose $(\mathrm{NaCMC})$, for $30 \mathrm{sec}$ with predetermined loads using a carver hydraulic press (Model C, Carver Inc., Menomomee Falls, WJ). Before each compression, the die $(12.5 \mathrm{~mm})$ and the flat faced punches were lubricated with a $2 \%$ magnesium stearate in benzene. After ejection, the tablets were stored over silica gel for $24 \mathrm{hr}$ to allow for elastic recovery and hardening and to prevent false low yield values. Their weights and dimensions were determined to within $\pm 1 \mathrm{mg}$ and 0.01 mm respectively.

Matrix tablets $(300 \mathrm{mg})$ were also prepared from the 500 to $1000 \mu \mathrm{m}$ size fraction of granules by compressing them for $30 \mathrm{sec}$ with pre determined loads on a hydraulic press as described above for tablets prepared by direct compression.

\subsection{Crushing Strength and Friability Tests}

The load required to diametrically break each tablet (crushing strength, CS) was determined using a Monsanto Hardness tester. The friability (F) of the tablets were determined using a friabilator (Veego scientific device, Mumbai, India) operated at 25 revolutions per minute for 4 minutes.

\subsection{Tablet Disintegration Test}

The disintegration times of the tablets were determined in distilled water at $37^{\circ} \mathrm{C}$ using a BP Manesty disintegration unit (Manesty Machines, Poole, UK). Six tablets from each formulation were placed on the wire mesh just above the surface of the distilled water in the tube and the apparatus was started simultaneously. The time at which each tablet disintegrated completely was observed and recorded. Determinations were made in triplicate and the mean time was recorded.

\subsection{Compaction Data Analysis}

The Heckel equation has by far been the most popular in recent years among pharmaceutical scientists, and many apparent yield pressure values ("in-die", $\mathrm{P}_{\mathrm{y}}$ ) and mean yield pressure values ("out-of-die") of active substances and tableting excipients have been published [13]. Despite the versatility of the Heckel equation however, 
drawbacks and limitations to its use have been reported. Some scientists have used more than one equation to try to eliminate the shortcomings of the others $[14,15]$. Hence, in this study, both Heckel and Kawakita plots have been used to assess the compressional behaviour of the materials.

\subsection{Heckel Analysis}

The plots constructed according to the Heckel equation [16] were used to characterize the consolidation behavior of the formulations:

$$
\operatorname{Ln}[1 /(1-\mathrm{D})]=\mathrm{KP}+\mathrm{A}
$$

where $\mathrm{D}$ is the ratio of the density of the powder mass at pressure $\mathrm{P}$ to the density of the powder mixture (i.e., relative density). $\mathrm{K}$, the slope of the straight portion of the graph, reflects the reduction in porosity or the resistance to volume reduction of granules and $\mathrm{A}$ is a constant. The yield pressure, $\mathrm{P}_{\mathrm{y}}$, is usually calculated as the reciprocal of the linear portion of the slope of the Heckel plot. The relative density $D_{A}$ was calculated from the intercept, A, using the Equation 2:

$$
\mathrm{D}_{\mathrm{A}}=1-\mathrm{e}^{\mathrm{A}}
$$

$D_{B}$, the relative density during the rearrangement phase was calculated from the difference between $\mathrm{D}_{\mathrm{A}}$ and $\mathrm{D}_{\mathrm{O}}$ (relative density of the granules at nil pressure).

\subsection{Kawakita Analysis}

The Kawakita equation [17] describes the relationship between the volume reduction of powder column and the applied pressure;

$$
\mathrm{C}=\left[\mathrm{V}_{0}-\mathrm{V} / \mathrm{V}_{0}\right]=[\mathrm{abP} / 1+\mathrm{bP}]
$$

where, $\mathrm{C}$, is degree of volume reduction, $\mathrm{V}_{0}$ is initial volume, $\mathrm{V}$ is volume of powder column under the applied pressure P. a, b are constants characteristic to powder being compressed. The equation above can be re arranged in linear form as:

$$
\mathrm{P} / \mathrm{C}=\mathrm{P} / \mathrm{a}+1 / \mathrm{ab}
$$

From the graphical presentation of $\mathrm{P} / \mathrm{C}$ versus $\mathrm{P}$, the constant "a", is given as a reciprocal of the slope from the linear portion of the plot and equivalent to the value of $\mathrm{C}$ at infinitely high pressures. $1 / \mathrm{ab}$ is the intercept. a, gives an indication of the maximum volume reduction available and is considered to describe the compressibility of a powder, while $b$ is considered to describe an inclination toward volume reduction. However, the actual physical meaning of the constants $a$ and $b$ have been in question [18]. Values of $1-a$ yield the initial relative density of the material, $\mathrm{D}_{\mathrm{I}}$ which has been shown to provide a measure of the packed initial relative density of tablets with the application of small pressure [19] The reciprocal of $\boldsymbol{b}$ is related to pressure term, $\mathrm{P}_{\mathrm{k}}$, which is the pressure, required to reduce the powder bed by $50 \%$ [20].

\subsection{Statistical Analysis}

The data were analyzed using correlation analysis and two-way ANOVA.

\section{Results and Discussion}

Powder compaction is a volume reduction process [16] and the Heckel equation is also based on volume change of a powder column during compression, hence the plots gave a general impression of the densification process of the powder column. Figure 1 shows representative Heckel plots for Okra gum matrices containing $90 \% \mathrm{w} / \mathrm{w}$ and $60 \% \mathrm{w} / \mathrm{w}$ of Okra gum prepared by direct compression and wet granulation.

The mean yield pressure, Py, was calculated from the regions of the plots showing the highest correlation coefficient of $\geq 0.990$ for all formulations (usually 84.93 $226.47 \mathrm{MN} / \mathrm{m}^{2}$ ). The intercept $\mathrm{A}$, was determined from the extrapolation of the line. The values of the mean yield pressure $\mathrm{P}_{\mathrm{y}}, \mathrm{D}_{\mathrm{A}}, \mathrm{D}_{\mathrm{B}}$ and $\mathrm{D}_{\mathrm{O}}$ are presented in Table 1 .

The $D_{A}$ values, which represent the total degree of packing at zero and low pressures increases as the concentration of the gum decreases. In general, formulations prepared by wet granulation gave higher $\mathrm{D}_{\mathrm{A}}$ values than those prepared by wet granulations. The $\mathrm{D}_{\mathrm{B}}$ values represent the particulate rearrangement phase in the early compression stages and tend to indicate the extent of particle or granule fragmentation, although fragmentation

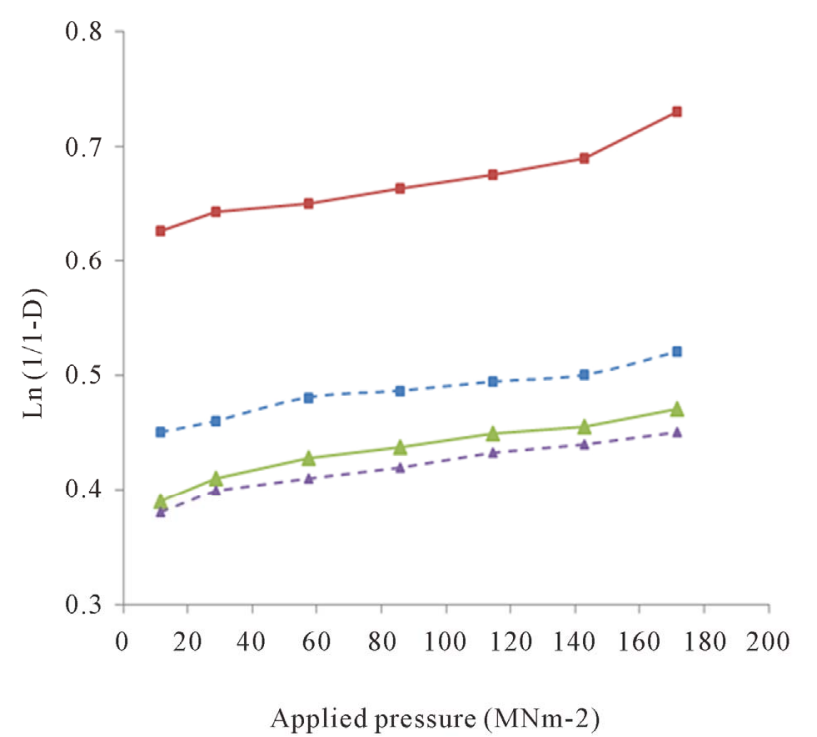

Figure 1. Heckel plots for Okra gum matrix tablet prepared by direct compression (------) and wet granulation (........). 匹, $90 \%$ w/w Okra gum; $\Delta, 60 \%$ w/w okra gum. 
Table 1. Parameters derived from Heckel and Kawakita plots for Okra gum matrices.

\begin{tabular}{|c|c|c|c|c|c|c|c|c|c|c|c|c|}
\hline \multirow{3}{*}{$\begin{array}{c}\text { Matrix } \\
\text { Tablet } \\
\text { Composition }\end{array}$} & \multicolumn{6}{|c|}{ Direct Compresion } & \multicolumn{6}{|c|}{ Wet Granulation } \\
\hline & \multicolumn{3}{|c|}{ Heckel Plot } & \multicolumn{3}{|c|}{ Kawakita plot } & \multicolumn{3}{|c|}{ Heckel Plot } & \multicolumn{3}{|c|}{ Kawakita plot } \\
\hline & $\mathrm{P}_{\mathrm{y}}$ & $\mathrm{D}_{\mathrm{A}}$ & $\mathrm{D}_{\mathrm{B}}$ & $\mathrm{P}_{\mathrm{k}}$ & $\mathrm{a}$ & $\mathrm{D}_{\mathrm{I}}$ & $\mathrm{P}_{\mathrm{y}}$ & $\mathrm{D}_{\mathrm{A}}$ & $\mathrm{D}_{\mathrm{B}}$ & $\mathrm{P}_{\mathrm{k}}$ & $\mathrm{a}$ & $\mathrm{D}_{\mathrm{I}}$ \\
\hline $10 \%$ Drug in Okra Gum & 2.82 & 0.299 & 0.099 & 0.026 & 0.966 & 0.034 & 2.396 & 0.7720 & 0.290 & 0.113 & 0.965 & 0.035 \\
\hline $20 \%$ Drug in Okra Gum & 2.14 & 0.373 & 0.173 & 0.429 & 0.970 & 0.030 & 2.137 & 0.9998 & 0.722 & 0.018 & 0.979 & 0.021 \\
\hline $30 \%$ Drug in Okra Gum & 1.48 & 0.491 & 0.208 & 0.076 & 0.971 & 0.029 & 1.481 & 0.0002 & 0.412 & 0.381 & 0.957 & 0.043 \\
\hline $40 \%$ Drug In Okra Gum & 1.47 & 0.493 & 0.293 & 0.063 & 0.970 & 0.003 & 1.449 & 0.0002 & 0.286 & 1.360 & 0.995 & 0.005 \\
\hline $10 \%$ Drug in $\mathrm{NaCMC}$ & 2.14 & 0.374 & 0.174 & 0.015 & 0.987 & 0.013 & 2.133 & 0.0001 & 0.141 & 0.524 & 0.982 & 0.018 \\
\hline
\end{tabular}

can occur concurrently with plastic and elastic deformation of constituent particles. The $\mathrm{D}_{\mathrm{B}}$ values increase with decrease concentration of the gum and formulations prepared by wet granulation exhibited higher values. This result indicates that granules undergo higher degree of fragmentation than powders. Powder particles were more resistant to movement once the initial phase of packing (as a result of die filling) had been completed. This could be attributed to the high cohesive forces likely present as a result of the powder's amorphous nature.

Figure 2 shows representative Kawakita plots for Okra gum matrices containing $90 \% \mathrm{w} / \mathrm{w}$ and $60 \% \mathrm{w} / \mathrm{w}$ Okra gum prepared by wet granulations and direct compression. A linear relationship was obtained at all compression pressures used with a 0.999 correlation coefficient for all formulation. Values of a and ab were obtained from the slope and intercept of the plot respectively. $\mathrm{D}_{\mathrm{I}}$, the initial relative density of the formulation were obtained from 1-a while $P_{k}$ values were obtained from the reciprocal of $b$. The $D_{I}$ values, which are measurements of the packed initial relative density of the formulation with application of small pressures or tapping [21] decreased as the concentration of the gum decreases. The $\mathrm{P}_{\mathrm{k}}$ and $\mathrm{P}_{\mathrm{y}}$ values, which are inverse measurements of the plastic deformation occurring during the compression process also decreased with a decrease in concentration of gum. In addition, formulations prepared by direct compression had lower $\mathrm{P}_{\mathrm{k}}$ values than those prepared by wet granulation while there was no significant difference between $\mathrm{P}_{\mathrm{y}}$ values of formulations prepared by direct compression and wet granulations. Thus, the method of preparation appears to have little or no effect on the onset of plastic deformation but the overall amount of plastic deformation occurring during the compression process was higher for formulations prepared by direct compression as indicated by the lower $\mathrm{P}_{\mathrm{k}}$ values. The results indicate that formulations prepared by direct compression underwent plastic deformation more easily and rapidly than those prepared by wet granulation. This also suggests that the wet granulation formulations are somewhat resistant to deformation. In tablets prepared by direct compression, formulations containing $90 \%$ of Okra

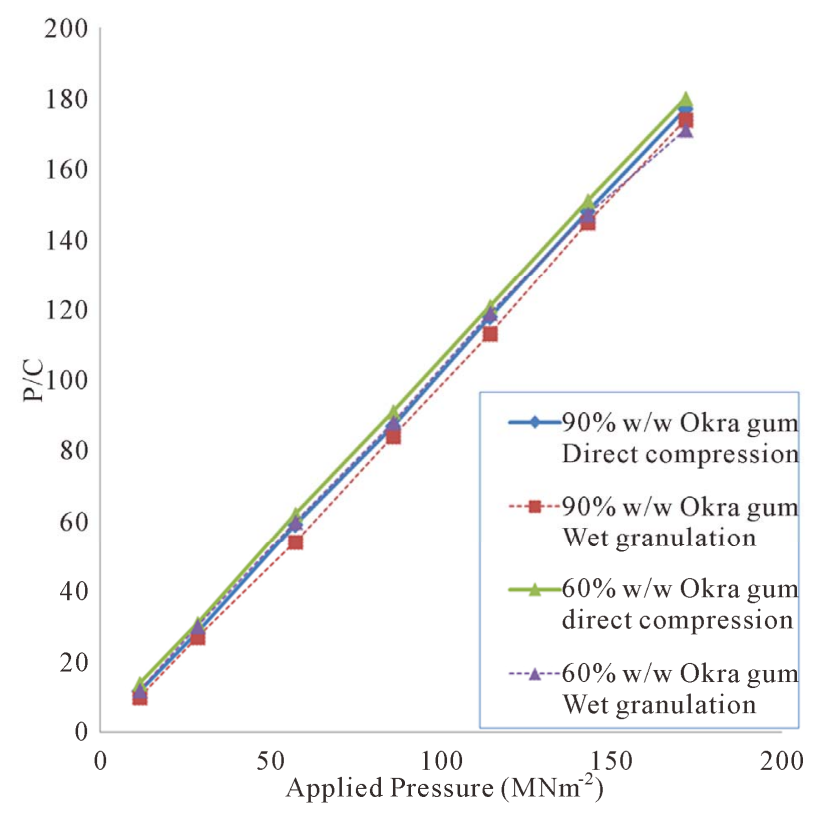

Figure 2. Kawakita plots for Okra gum matrix tablet prepared by direct compression and wet granulation.

gum exhibited the highest amount of total plastic deformation and gave the best packing as evidenced by the low value of "a".

The mechanical strength of a tablet is associated with the resistance of the solid specimen to fracturing and attrition. An acceptable tablet must remain intact at all stages i.e. during production, packaging, warehousing, distribution, dispensing and administration by the patient. Thus, an integrated part of the formulation and production of tablets is the determination of their mechanical strength which are quantifiable by the crushing strength (CS) and friability (F) of the tablets. There are no clear official limits for acceptance or rejection of tablet batches probably because the desired crushing strength is largely dependent on the intended use of the tablet while tablets that lose less than $1 \%$ of their weight during the friability test are generally considered acceptable [22]. The values of crushing strength and friability for all formulation are presented in Table 2. The crushing strength generally decreases with a decrease in the concentration 
Table 2. Values of Crushing strength (CS), Friability (FR), Crushing strength—Friability ratio (CSFR) and Disintegration time (D) for Okra gum matrices.

\begin{tabular}{|c|c|c|c|c|c|c|c|c|}
\hline \multirow{2}{*}{$\begin{array}{c}\text { Matrix } \\
\text { Tablet } \\
\text { Composition }\end{array}$} & \multicolumn{4}{|c|}{ Direct Compression } & \multicolumn{4}{|c|}{ Wet Granulation } \\
\hline & CS & FR & CSFR & $\mathrm{D}$ & CS & FR & CSFR & $\mathrm{D}$ \\
\hline $10 \%$ Drug In Okra Gum & 44 & 1.50 & 29.33 & 84.8 & 16.6 & 1.10 & 15.09 & 146 \\
\hline $20 \%$ Drug in Okra Gum & 28 & 1.88 & 14.89 & 67.3 & 46 & 1.70 & 27.06 & 106.7 \\
\hline $30 \%$ Drug in Okra Gum & 27 & 2.02 & 13.37 & 65.8 & 45.3 & 1.76 & 25.73 & 79.0 \\
\hline $40 \%$ Drug in Okra Gum & 25 & 2.21 & 11.31 & 64.8 & 41.2 & 1.83 & 22.51 & 68.5 \\
\hline $10 \%$ Drug in $\mathrm{NaCMC}$ & 13 & 0.52 & 25.00 & 45.1 & 51.01 & 0.62 & 82.27 & 63.3 \\
\hline
\end{tabular}

of the gum while the friability increased for both formulations prepared by both direct compression and wet granulation. It is reasonable to assume that the presence of the polymer gum (binder) plays an important role in the formation of intergranular bonds. The polymer may fuse together locally and form binder bridges between the surfaces. The more the amount of polymer present, the more of such bridges and hence the resultant increase in strength.

Tablets prepared by direct compression showed lower bond strength and higher friability values than those prepared by wet granulations probably due to the fact that different types of adsorption bonds may be active between granule surfaces (i.e. binder-binder, binder-substrate and substrate-substrate bonds) compared to only intermolecular forces in powders. Moreover, the addition of water in wet granulation probably led to the formation of more solid bridges between the particles [23]. The values of crushing strength and friability provide a measure of tablet strength and weakness respectively. Thus the CSFR ratio can be a useful index of tablet quality. Generally, the higher the CSFR values, the stronger the tablet. From the data presented in Table 2, the value of CSFR decreases with a decrease in gum concentration and tablets prepared by wet granulations had higher CSFR than those prepared by direct compression. Statistical analysis showed that tablets prepared by wet granulation showed significantly $(p<0.001)$ higher values of CSFR than those prepared by direct compression. The disintegration times of the formulation presented in Table 2 show that tablets prepared by direct compression disintegrated faster than those prepared by wet granulations. Moreover, disintegration became faster as gum concentration decreases.

\section{Conclusion}

The results suggest that the method of preparation appears to have little effect on the onset of plastic deformation of Okra gum matrices but significantly affected the total plastic deformation during compression. Tablets prepared by wet granulation were stronger but disintegrated more slowly than tablets formulated by direct compression. In addition, tablet strength generally decreases with a decrease in the concentration of the gum.

\section{REFERENCES}

[1] A. Jain, Y. Gupta and S. K. Jain, "Perspectives of Biodegradable Natural Polysaccharides for Site-Specific Drug delivery to the colon," Journal of Pharmacy \& Pharmaceutical Sciences, Vol. 10, No. 1, 2007, pp. 86-128. www.cspsCanada.org

[2] P. B. Malafaya, G. A. Silva and R. L. Reis, "NaturalOrigin Polymers as Carriers and Scaffolds for Biomolecules and Cell Delivery in Tissue Engineering Applications," Advanced Drug Delivery Reviews, Vol. 59, No. 4-5, 2007, pp. 207-233. doi:10.1016/j.addr.2007.03.012

[3] A. Shirwaikar, S. L. Prabu and G. A. Kumar, "Herbal Excipients in Novel Drug Delivery Systems," Indian Journal of Pharmaceutical Sciences, Vol. 70, No. 4, 2008, pp. 415-422. doi:10.4103/0250-474X.44587

[4] C. E. Beneke, A. M. Viljoen and J. H. Hamman, "Polymeric Plant-Derived Excipients in Drug Delivery," Molecules, Vol. 14, No. 7, 2009, pp. 2602-2620. doi:10.3390/molecules 14072602

[5] P. F. Builders, M. B. Agbo, T. Adelakun, L. C. Okpako and A. A. Attama, "Novel Multifunctional Pharmaceutical Excipients Derived from Microcrystalline CelluloseStarch Microparticulate Composites Prepared by Compatibilized Reactive Polymer Blending," International Journal of Pharmaceutics, Vol. 388, No. 1-2, 2010, pp. 159-167. doi:10.1016/j.ijpharm.2009.12.056

[6] J. A. Boustra and H. E. Junginger, "Hydrogels," In: J. Swarbrick and J. C. Boylan, Eds., Encyclopedia of Pharmaceutical Technology Vol. 7, Marcel Dekker, Inc., New York, 1993, p. 441.

[7] R. C. Rowe, P. J. Shesky and M. E. Quinn, "Hand Book of Pharmaceutical Excipients," 4th Edition, Pharmaceutical Press, London, 2003.

[8] M. Agarwal, R. Srinivasan and A. Mishra, "Study on Flocculation Efficiency of Okra Gum in Sewage Waste Water," Macromolecular Materials and Engineering, Vol. 286, No. 9, 2001, pp. 560-563. doi:10.1002/1439-2054(20010901)286:9<560::AID-MA ME560>3.0.CO;2-B

[9] N. Tavakoli, N. Ghasemi, R. Taimouri and H. Hamishehkar, "Evaluation of Okra Gum as a Binder in Tablet 
Dosage Forms," Iranian Journal of Pharmaceutical Research, Vol. 3, Suppl. 2, 2004, pp. 47-49.

[10] M.O Emeje, C. Y. Isimi and O. O. Kunle, "Evaluation of Okra Gum as a Dry Binder in Paracetamol Tablet Formulations," Continental Journal of Pharmaceutical Sciences, Vol. 1, 2007, pp. 15-22.

[11] V. D. Kalu, M. A. Odeniyi and K. T. Jaiyeoba, "Matrix Properties of a New Plant Gum in Controlled Drug Delivery," Archives of Pharmacal Research, Vol. 30, No. 7, 2007, pp. 884-889. doi:10.1007/BF02978841

[12] M. M. Talukdar, A. Michoel, P. Rombant and R. Kinget "Comparative Study on Xanthum Gum and Hydroxypropylmethyl Cellulose as Matrices for Controlled Release Drug Delivery. I. Compaction and in Vitro Drug Release Behavior," International Journal of Pharmaceutics, Vol. 129, No. 1-2, 1996, pp. 233-241. doi:10.1016/0378-5173(95)04355-1

[13] J. M. Sonnergaard," A Critical Evaluation of the Heckel Equation," International Journal of Pharmaceutics, Vol. 193, No. 1, 1999, pp. 63-71. doi:10.1016/S0378-5173(99)00319-1

[14] I. Krycer, D. G. Pope and J. A. Hersey, "The Interpretation of Powder Compaction Data-A Critical Review," Drug Development and Industrial Pharmacy, Vol. 8, No. 3, 1982, pp. 307-342. doi:10.3109/03639048209022103

[15] T. Comoglu, "An Overview of Compaction Equations," Journal Faculty of Pharmacy, Vol. 36, No. 2, 2007, pp. 123-133.

[16] W. Heckel, "Density-Pressure Relationship in Powder Compaction," Transactions of the Metallurgical Society of AIME, Vol. 221, 1961, pp. 671-675.
[17] K. Kawakita and K. H. Ludde, "Some Considerations on Powder Compression Equations," Powder Technology, Vol. 4, No. 2, 1971, pp. 61-68.

[18] G. Alderborn and C. Nystrom, "Studies on Direct Compression of Tablets. IV. The Effect of Particle Size on the Mechanical Strength of Tablets," Acta Pharmaceutica Suecica, Vol. 19, No. 5, 1982, pp. 381-390.

[19] O. O. Odeku and O. A. Itiola, "Evaluation of Khaya Gum as a Binder in a Paracetamol Tablet Formulation," Pharmacy and Pharmacology Communications, Vol. 4, No. 4, 1998, pp. 183-188.

[20] P. Shivanand and O. L. Sprokel, "Compaction Behaviour of Cellulose Polymers," Powder Technology, Vol. 69, No. 2, 1992, pp. 177-184. doi:10.1016/0032-5910(92)85072-4

[21] F. Podczeck and M. Sharma, "The Influence of Particle Size and Shape of Components of Binary Powder Mixtures on the Maximum Volume Reduction Due to Packing," International Journal of Pharmaceutics, Vol. 134, No. 1, 1996, pp. 41-47. doi:10.1016/0378-5173(95)04420-5

[22] O. O. Odeku and O. A. Itiola, "Evaluation of the Effects of Khaya Gum on the Mechanical and Release Properties of Paracetamol Tablets," Drug Development and Industrial Pharmacy, Vol. 29, No. 3, 2003, pp. 311-320. doi:10.1081/DDC-120018205

[23] J. Sujja-Areavath, D. L. Munday, P. J. Cox and K. A. Khan, "Release Characteristics of Diclofenac Sodium from Encapsulated Natural Gum Mini-Matrix Formulations," International Journal of Pharmaceutics, Vol. 139, 1996, pp. 53-62. doi:10.1016/0378-5173(96)04573-5 